\title{
Строение краевых образований последнего оледенения в районе озера Перхъявр (север Кольского полуострова)
}

Вашков А.А.

Геологический институт КНЦРАН, Anamuты, vashkov@geoksc.apatity.ru

Аннотация. Комплекс грядового рельефа у озера Перхъявр построен серией надвиговых гляциодислокаций. С внешней стороны этого комплекса в строении отдельной гряды установлены флювиогляциальные аккумуляции. Они сопоставляются с внешним краем активного льда в краевой зоне оледенения. Расположение комплекса краевых образований в регионе указывает на скачкообразный ход сокращения ледникового покрова на севере Кольского полуострова. Ареальный тип дегляциации сменялся периодами фронтального сокращения ледникового покрова.

Ключевые слова: конечно-моренные образования, моренная гряда, гляциодислокации, базальный тилл, флювиогляциальные отложения, дегляциация, осцилляция.

\section{Structure of ice-marginal deposits of the last glaciation near the Perkhyavr Lake (the north of the Kola Peninsula)}

\author{
Vashkov A.A. \\ Geological Institute of the Kola Science Centre of RAS, Apatity,vashkov@geoksc.apatity.ru
}

\begin{abstract}
The ridge relief complex near the Perkhyavr Lake is composed of series of thrust glaciodislocations. Fluvioglacial deposits were determined in structure of the distinct ridge at the outer side of the complex. They are compared to outer margin of active glacier in the ice-marginal zone. The position of ice-marginal, deposits in the region indicates a discontinuous character of deglaciation in the north of the Kola Peninsula. The areal deglaciation alternated with periods of frontal reduction of the ice cover.
\end{abstract}

Key words: ice-marginal deposits, moraine ridge, glaciodislocations, basal till, fluvioglacial deposits, deglaciation, oscillation.

Исследование строения краевых образований актуально в связи с необходимостью понимания процессов ледникового морфогенеза и закономерностей распределения строительных полезных ископаемых, а также для проведения реконструкции динамики последнего ледникового покрова и дегляциации региона.

На севере Кольского полуострова краевые образования были ранее изучены в районе оз. Мартимъявр (бассейн р. Воронья). Здесь распространен грядово-кольцевой рельеф, который формирует полосы шириной от 0.5 до 10 км, протяженностью 50 и более километров. Впервые грядово-кольцевые формы ледникового рельефа были описаны в 1960-ых годах, их происхождение связывалось с массивами мёртвого льда (Арманд, 1964). В 1990-ых годах были получены данные по строению грядово-кольцевого рельефа у оз. Мармитьявр (Евзеров и др., 1993). Позже этот участок был соотнесен с одним из поясов конечно-моренных образований. Наличие надвиговых гляциодислокаций в строении гряд позволило сделать вывод о том, что грядовый рельеф формировался на контакте активного ледника и поля мертвого льда (Евзеров, 2015; Kolka et al., 2008). Проведенные в 2017 г. полевые работы в районе озера Мартимъявр позволили установить основные закономерности морфологии рельефа. Были выявлены фронтальные, радиальные гряды, а также гряды сложной плановой ориентировки и гряды-увалы на дистальном крае полосы. В строении гряд были обнаружены надвиговые и складчато-надвиговые гляциодислокации (Вашков, Носова, 2019).

В 2019 г. были проведены полевые работы у оз. Перхъявр (бассейн р. Воронья) (рис. 1). Район работ расположен на участке со значительно расчлененной поверхностью. Верхний ярус рельефа составляют крупные холмы-массивы абсолютной высотой 180-260 м, на поверхности которых повсеместно вскрываются породы кристаллического фундамента. На нижнем ярусе (65-100 м) расположены озерные котловины и речные долины. Грядовые формы рельефа не имеют строгой вы- 


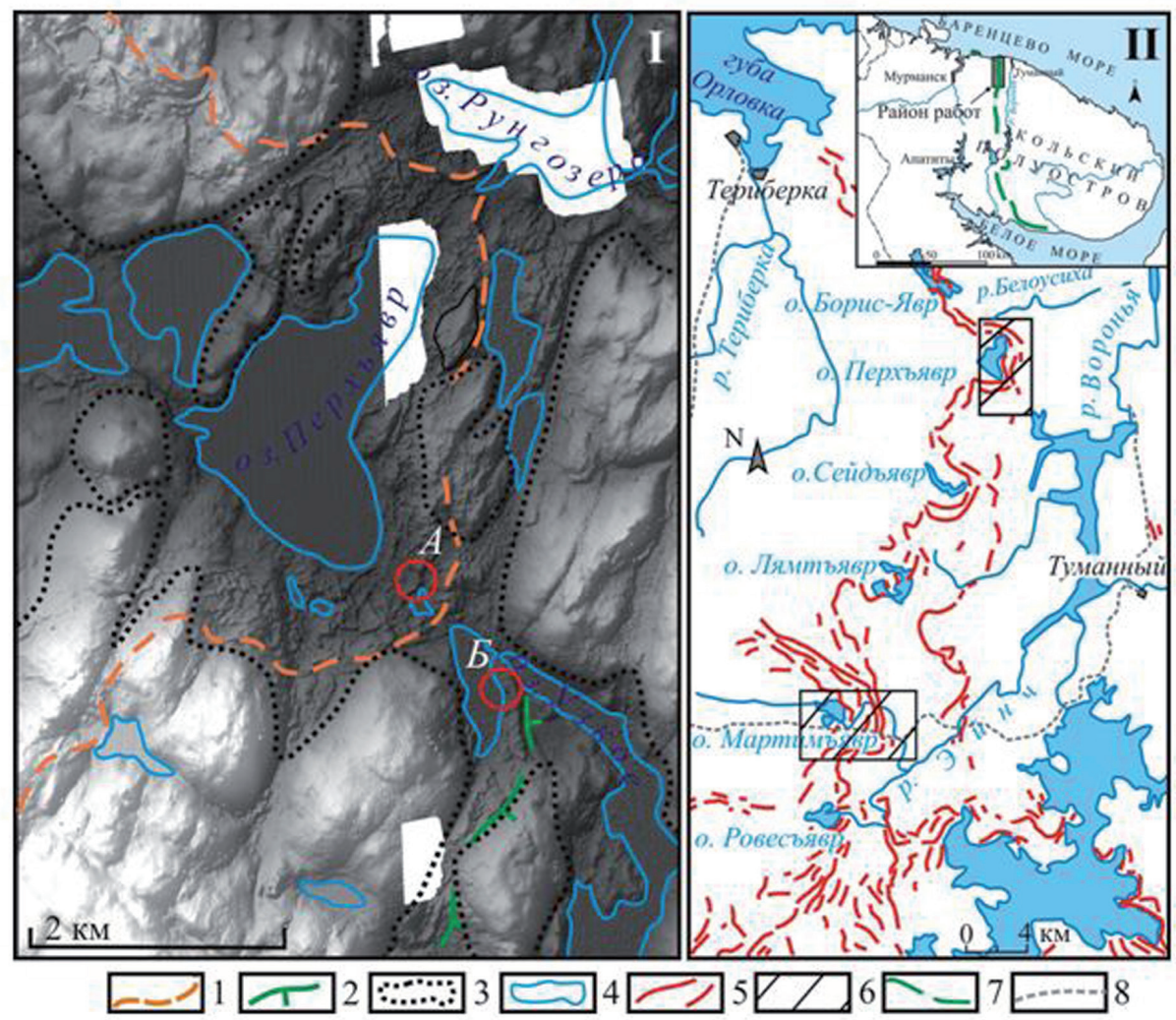

Рис. 1. Схема рельефа в районе оз. Перхъявр (I, цифровая модель рельефа ArctikDEM) и положение краевых образований (II): 1 - внешний край полосы фронтальных гряд; 2 - полоса гряд-увалов; 3 - холмы, связанные с выступами кристаллического фундамента; 4 - озера; 5 - краевые образования региона; 6 - участки исследований; 7 - краевые образования (на врезке); 8 - дороги.

Fig. 1. Scheme of the relief near the Perkhyavr Lake (I, digital relief model ArctikDEM ) and position of ice-marginal deposits (II): 1 - the outer margin of the band of frontal ridges; 2 - band of fluvioglacial ridges; 3 - hill associated with the bedrock; 4 - lakes; 5 - ice-marginal deposits of the study area; 6 - study areas; 7 - ice-marginal deposits (on the inset map); 8 - roads.

сотной привязки. Преимущественно они сконцентрированы на нижнем ярусе рельефа на абсолютных отметках 80-110 м, но в юго-западном направлении поднимаются на склоны холмов-массивов до абсолютных отметок 200-220 м.

В ходе работы были изучены 3 обнажения (расчистки на склонах гряд, шурфы). Проводилось подробное изучение структурно-текстурных особенностей ледниковых и водно-ледниковых осадков, их цвет, гранулометрический состав, текстуры и наличие отдельных слоёв, линз, вкраплений. Производились замеры мощности отдельных слойков и линз, а также азимут и угол падения слоистости. Для определения направлений нагнетания обломочного материала ледником применялся структурный метод массовых замеров плоскостей сланцеватости и слоистости, а также длинных осей галек и валунов в тилле (Аболтиньш, 1989). Геологические данные сопоставлялись с формами рельефа, которые прослеживались с помощью цифровой модели рельефа ArctikDEM (разрешение - 2 м).

В полосе грядового рельефа шириной 0.4-0.7 км у юго-восточного берега оз. Перхъявр было установлено несколько типов мезоформ, сходных по своим характеристикам с рельефом у оз. Мартимъявр (Вашков, Носова, 2019). Гряды отличаются друг от друга морфологически, по своему строению и по плановому расположению относительно фронта активного ледника (рис. 1, I). Наиболее широко развиты фронтальные гряды. Они извилистые в плане, длиной 0.2-0.45 км, шириной 45-65 м, отличаются наибольшей высотой (до 10-14 м) и крутыми склонами. Склоны западной экспозиции ровные или вогнутые, крутизной $14-25^{\circ}$. Склоны восточной экспозиции крутизной 20-32 ${ }^{\circ}$, иногда ступенчатые. Фронтальным грядам характерны хорошо выраженные узкие гребни, иногда шириной все- 
го в 2-3 м. Эти формы выстраиваются в цепочки. Всего в районе у оз. Перхъявр установлено не менее 3 параллельных друг другу цепочек. Гряды сложной плановой ориентировки размещаются между фронтальными грядами, иногда примыкают к ним. Их длина не превышает 0.15 км, высота составляет 3-7 м, склоны крутизной до 25-30. Склоны, обращенные в сторону озерных и заболоченных котловин, отличаются большей крутизной и выраженной бровкой. На дистальном крае полосы параллельно-грядового рельефа выражена гряда-увал. Она удалена на 1-1.5 км в юго-восточном направлении от фронтальных гряд. Расположена форма согласно простиранию полосы фронтальных гряд, в понижении коренного рельефа. Гряда-увал разделяет собой две озерные котловины. Южным окончанием она примыкает к крупному холму-массиву из коренных пород, далее к югу на склонах этого холма не прослеживается. Общая длина гряды-увала 0.9 км, ширина 0.11-0.26 км, высота от 5-8 до 12-15 м относительно прилегающих к нему озерных котловин. Отличается от других аккумулятивных форм района платообразной поверхностью с отдельными валообразными гребнями и разделяющими их западинами глубиной 1.5-3 м. Склоны гряды в сторону прилегающих озерных котловин достаточно крутые за счет их абразионной переработки.

Исследование гряд фронтальной плановой ориентировки проводилось на хорошо выраженной в рельефе форме меридионального простирания с узким и высоким гребнем в двух шурфах (абсолютные отметки 86-87 м над уровнем моря; N 6901'14.3'”, Е 35³1'00.4'”, рис. 1, I, А; рис. 2, А). Поверхность гряды с большим количеством валунов, диаметром до 1.5 м. В шурфе на гребне гряды у восточного склона вскрыты (здесь и далее по тексту описание дано сверху - вниз разреза):

1. Торф красновато-коричневый, плотный, состоящий преимущественно из остатков кустарниковой растительности и трав. Мощность возрастает у бровки восточного склона гряды до 0.6 м. В центральной части гребня гряды и на западном склоне торф отсутствует.

2. Песок коричневато-серого цвета, глинистый, разнозернистый, преимущественно среднезернистый, с редким гравием, с пятнами песка светло-серого. Толщина слоя до 0.2 м.

3. Песчано-гравийно-галечная смесь грубая, пестрого цвета, с валунами, глинистый, связная до состояния конгломерата железистым цементом мощностью свыше 0.2 м.

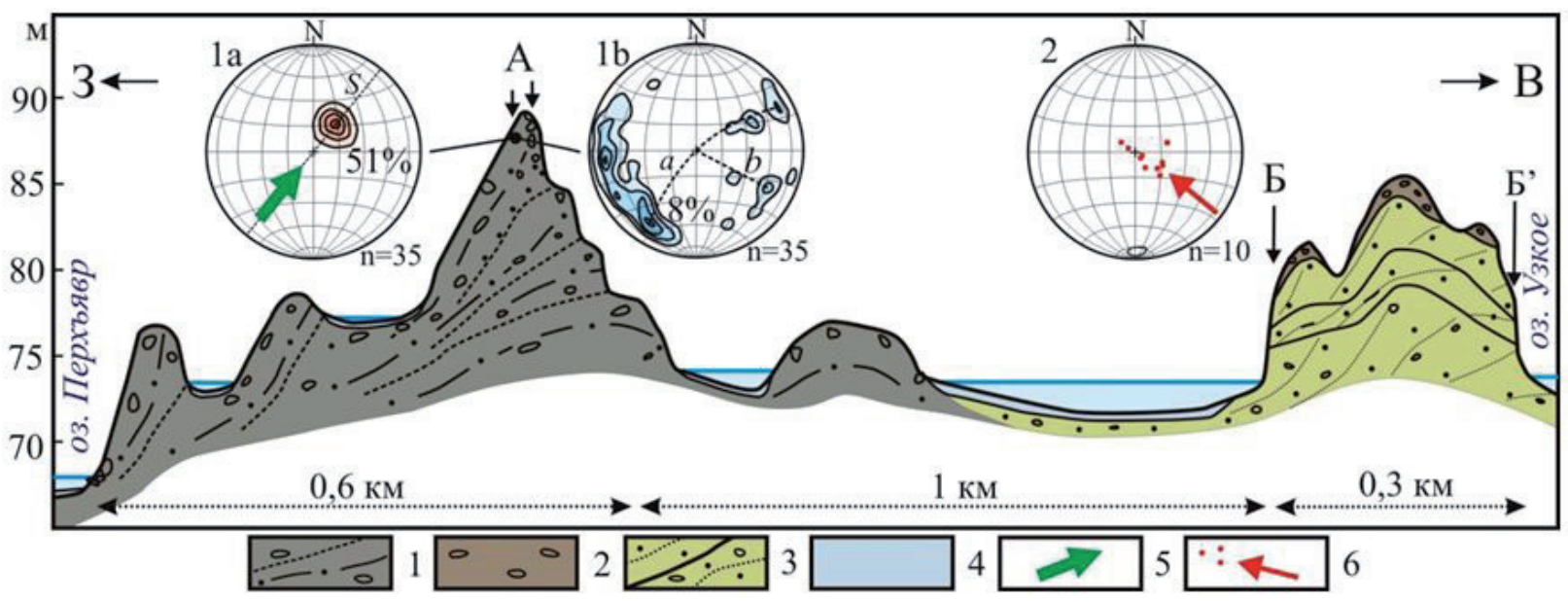

Рис. 2. Строение фронтальных гряд и гряды-увала в районе оз. Перхъявр: 1 - базальный тилл в гляциодислокациях; 2 - абляционный тилл; 3 - флювиогляциальные отложения; 4 - озерные и болотные отложения; 5 - направление давления активного льда (на диаграмме 1a); 6 - направление стока талых ледниковых вод и распределение полюсов слоистости (на диаграмме 2). Диаграммы 1а и 2 - для полюсов сланцеватости, диаграмма $1 \mathrm{~b}$ - для линейных элементов ориентировки крупнообломочного материала. На всех диаграммах использована сетка Шмидта, нижняя полусфера.

Fig. 2. Structure of the frontal ridge and the fluvioglacial ridge near the Perkhyavr Lake: 1 - basal till in glaciodislocations; 2 - ablation till; 3 - fluvioglacial deposits; 4 - lacustrine and polustrine deposits; 5 - direction of active ice movement (on the diagram 1a); 6 - flow direction of melt water and distribution of poles of foliation (on the diagram 2). Diagrams 1a and 2 are for poles of foliation, diagram $1 \mathrm{~b}$ is for linear elements of the orientation of coarse-clastic material. On all the diagrams, the lower hemisphere of the Schmidt net is used. 
В шурфе на западном склоне гряды в 2 м ниже гребня гряды вскрыты:

1. Песок коричневато-серый с пятнами желто-коричневого цвета, разнозернистый, преимущественно мелкозернистый, с гравием, галькой, валунами и незначительным числом алевритовых частиц. Перекрыт маломощной современной почвой. Мощность слоя неравномерная, 0.34-0.42 м.

2. Песок оливково-серый, разнозернистый, преимущественно мелкозернистый, глинистый, грубый, с песком, гравием, галькой. Песок со сланцеватой текстурой, которая выражена за счет отдельности толщиной 1-2 мм, разделенной присыпками песка светло-серого, мелкозернистого. Отдельность наклонена к котловине оз. Перхъявр. В слое имеются признаки слоистости за счет тонких прослоек песка светло-серого, средне- и мелкозернистого, с редкими зернами гравия.

Исследование строения гряды-увала произведено в двух расчистках абразионных уступов озер, которые вскрывают западный и северо-восточный склоны гряды (рис. 2 Б, Б'). Наиболее представительный разрез высотой 5,4 м находится на западном склоне гряды на берегу озера с урезом

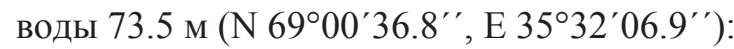

1. Песчано-гравийно-галечная смесь с отдельными валунами, серо-коричневая, грубая, не сортированная, не промытая, с прослоями песка оливково-коричневого, разнозернистого, под маломощной современной почвой. Мощность слоя -0.4 м

2. Переслаивание песков разнозернистых, средне- мелкозернистых с песками тонкозернистыми, а также с отдельными прослойками и линзами песчано-гравийной смеси. Пески желтоватокоричневого цвета, пески тонких фракций - оливково-серые. Слоистость косая, падает по азимутам 294-326º под углами 14-23 ${ }^{\circ}$. Подошва пачки неровная, со следами размыва нижележащих осадков. Мощность пачки -2.35 м.

3. Песок среднезернистый светло-коричневый, с примесью песка крупнозернистого, гравия и гальки и прослоями толщиной до 0.2 м гравийно-галечной смеси. В интервале 0.3-0.4 м от кровли слоя отмечаются прослои песка тонкозернистого, глинистого. Слоистость пачки субпараллельная, с уклоном по азимуту $293-310^{\circ}$ под углом $6^{\circ}$. Мощность -1.05 м.

4. Песок разнозернистый, преимущественно крупнозернистый, с гравием, желтоватокоричневый, промытый, слоистый. Слоистость косая, падает по азимуту $291^{\circ}$ под углом $22^{\circ}$. Мощность слоя видимая (залегает ниже уреза воды в озере) - более 1.6 м.

Строение и морфометрические характеристики исследованной фронтальной гряды в целом идентичны комплексу грядового рельефа в районе котловины озера Мартимъявр (Евзеров и др., 1993; Евзеров, 2015). На это указывают выявленные в строении гребня гряды плотно цементированные железистым цементом гравийно-галечные смеси, а также дислоцированные базальные тиллы на её склоне (Вашков, Носова, 2019). Пески глинистые оливково-серого цвета сопоставляются нами с базальным тиллом, характерным для региона (Семенова, 2004; Евзеров, 2017). Исследование ориентировки сланцеватости и крупнообломочного материала указывает, что тилл залегает либо на крыле гляциоскладки, либо представляет собой чешую, характерную для надвиговых гляциодислокаций региона (Евзеров и др., 1993; Kolka at all, 2008). Нагнетание материала происходило с югозапада на северо-восток (рис. 2, диаграммы 1a, 1b). В пользу надвиговой природы структуры указывает морфология её восточного склона с несколькими террасовидными площадками, разделенными крутыми участками склона (до $38^{\circ}$ ). Наличие цементированного гравийно-галечного материала в гребне говорит о сложном строении гряды. На дистальной части гляциоструктур тут могут залегать деформированные флювиогляциальные осадки.

По характеру слоистости и степени сортировки флювиогляциальные аккумуляции грядыувала могут относиться к фации флювиогляциальной дельты. Отсутствие в разрезах деформаций в виде сколов указывает на отложение осадков на субстрат без блоков мёртвого льда. Преобладающее северо-западное направление падения слоистости указывает на сток талых ледниковых вод в северных румбах, то есть в основном параллельно простиранию фронтальных гряд, в сторону оз. Рунгозеро в современной долине р. Белоусиха. Это могло происходить в случае блокирования мертвым льдом долины с озером Узкое, которая открыта в юго-восточном направлении. 
Полоса грядового рельефа в районе оз. Перхъявр сопоставляется с одной фазой деградации последнего ледникового покрова. Она могла происходить в среднем дриасе (DR 2) (Евзеров, 2015). Три параллельные друг другу цепочки фронтальных гряд соотносятся нами с не менее, чем в тремя осцилляциями. В то же время в грядовом рельефе у оз. Мартимъявр отмечается не менее 6 осцилляторных цепочек (Вашков, Носова, 2019). Гряда-увал может обозначать положение непосредственного края активного ледникового покрова и его границу с полем мертвого льда в современной долине р. Воронья.

Таким образом, полосы краевых образований на севере Кольского полуострова имеют упорядоченную морфологию и строение. Складчатые и надвиговые гляциодислокации фронтальных гряд указывают на отдельные краткосрочные подвижки ледникового покрова, которые приводили к деформации насыщенного дебрисом льда в краевой зоне. В состав гляциоструктур могли включаться ранее отложенные рыхлые осадки. Установлено два типа дегляциации на севере Кольского полуострова: ареальная и фронтальная. Первый тип может быть связан с периодами относительных потеплений, второй тип - с похолоданиями и повторными подвижками активизированного ледникового покрова. Полученные результаты будут использованы в работах по установлению особенностей ледникового морфогенеза и особенностей динамики последнего ледникового покрова в регионе.

\section{Благодарность}

Автор благодарит А.В. Гончаренко и А.Д. Моисеенко за помощь в проведении полевых работ, а также В.В. Кольку, О.П. Корсакову, Д.С. Толстоброва, О.Ю. Носову за обсуждение материала.

Работа выполнена по теме НИР 0226-2019-0054 лаборатории №43 Геологического института КНЦ РАН и при поддержке гранта РФФИ №18-35-00054-мол_а.

\section{Литература}

1. Аболтиньш О.П. Гляциоструктура и ледниковый морфогенез. Рига: Зинатне. 1989. 284 c.

2. Арманд Н.Н. Грядово-кольцевой рельеф морены// Рельеф и геологическое строение осадочного покрова Кольского полуострова. М.-Л.: Наука. 1964. С. 68-71.

3. Вашков А.А., Носова О.Ю. Строение грядового рельефа и особенности дегляциации в районе озера Мартимъявр (Кольский полуостров) // Вестник Воронежского государственного университета. Серия: Геология. 2019. № 2. С. 26-35.

4. Евзеров В.Я. Горбунов Е.О., Колька В.В. Краевые ледниковые образования позднего дриаса в северной и центральной частях Кольского полуострова // Четвертичные отложения и новейшая тектоника ледниковый областей Восточной Европы. Апатиты. 1993. С. 26-38.

5. Евзеров В.Я. Литология морены поздневалдайского оледенения западной части Кольского полуострова // Вестник Мурманского государственного технического университета. 2017. Т. 20. № 1-1. С. 48-59. DOI: $10.21443 / 1560-9278-2017-20-1 / 1-48-59$

6. Евзеров В.Я. Строение и формирование внешней полосы одного из поясов краевых образований поздневалдайского ледникового покрова в Кольском регионе // Вестник Воронежского государственного университета. Серия: Геология. 2015. № 4. С. 5-12.

7. Семенова Л.Р. Ледниковая геология Кольского полуострова (поздний плейстоцен)// Автореферат диссертации на соискание ученой степени кандидата геолого-минералогических наук по специальности 25.00.01 - Общая и региональная геология: СПб. ВСЕГЕИ. 2004. 36 с.

8. Kolka V., Korsakova O., Nikolaeva S., Yevzerov V. The Late Pleistocene interglacial, late glacial landforms and Holocene neotectonics of the Kola Peninsula // ICG excursion. № 34. August 14-23. 2008. 72 p. 